\title{
Pengukuran Kinerja Web Brinet System Dengan Metode IT Balanced Scorecard
}

\author{
Sandy Kosasi \\ Program Studi Sistem Informasi, STMIK Pontianak \\ Jln. Merdeka No. 372 Pontianak, Kalimantan Barat \\ E-mail: sandykosasi@yahoo.co.id dan sandykosasi@stmikpontianak.ac.id \\ Masuk: 17 Februari 2014; Direvisi: 10 Juni 2014; Diterima: 27 Juni 2014
}

\begin{abstract}
Web Brinet System (WBS) application has an important contribution to improve services to Putussibau customers of PT Bank Rakyat Indonesia (BRI). This application mainly functions to simplify deposit and remittance, ATM card requests, notifications, and e-banking registration. The purpose of application performance measurement is to find out how far the application can give benefits and how to improve the application system. The measurement of application performance uses IT balanced scorecard method based on each perspective through descriptive analysis, resulting the highest perspective on the future orientation is $24.32 \%$, the second operational excellence is $24.09 \%$, the third users' orientation is $23.81 \%$, and the lowest contribution of organization is $22.33 \%$ from the target of each perspective of $25 \%$. The final result of the achievement is $94.55 \%$, showing that this value is at level A or categorized as very good.
\end{abstract}

Keywords: application, performance measurement, descriptive analytic, IT balanced scorecard.

Abstrak. Penerapan Web Brinet System (WBS) memiliki kontribusi penting untuk meningkatkan pelayanan kepada nasabah PT Bank Rakyat Indonesia (BRI) Cabang Putussibau. Aplikasi ini memiliki fungsi utama untuk memudahkan penyetoran dan pengiriman uang, permintaan kartu ATM, notifikasi, dan daftar EBanking. Tujuan pengukuran kinerja aplikasi adalah untuk mengetahui sejauh mana aplikasi sudah dapat memberikan manfaat dan yang masih membutuhkan penyempurnaan. Pengukuran kinerja aplikasi menggunakan metode IT Balanced Scorecard sesuai masing-masing perspektif melalui deskriptif analitis, dengan hasil tertinggi pada orientasi masa depan (24,32\%), kedua keunggulan operasional (24,09\%), ketiga orientasi pengguna (23,81\%), dan terendah kontribusi organisasi $(22,33 \%)$ dari target masing-masing perspektif sebesar $25 \%$. Hasil akhir pencapaian sebesar 94,55\%, dimana telah berada pada level A atau very good.

Kata Kunci: aplikasi, pengukuran kinerja, deskriptif analitis, IT balanced scorecard.

\section{Pendahuluan}

PT. Bank Rakyat Indonesia (BRI) Cabang Putussibau senantiasa memberikan pelayanan yang maksimal dalam pengelolaan transaksi perbankan. Membangun relasi yang harmonis antara pihak stakeholder dengan pihak perbankan adalah penting, mengingat semakin lama semakin banyak pesaing, baik pesaing dari industri perbankan yang sejenis maupun berkembangnya lembaga keuangan bukan bank yang akhir-akhir ini semakin banyak menawarkan berbagai investasi menarik kepada masyarakat sekitarnya. Kenyataan ini mengharuskan pihak manajemen harus selalu memperhatikan dan melakukan penyempurnaan dalam pemanfaatan teknologi informasi untuk memberikan pelayanan yang maksimal kepada nasabah. Untuk kegiatan operasional sudah menggunakan aplikasi Web Brinet System (WBS) sejak tahun 2010. Sistem aplikasi ini memiliki fungsi utamanya melayani nasabah untuk 
penyetoran, pengiriman uang, permintaan kartu ATM, notifikasi, dan daftar e-banking. Pemanfaatan teknologi informasi saat ini tidak lagi hanya berperan sebagai service provider saja, melainkan telah bergeser kepentingannya hingga pada tingkat strategic partner (Keyes, 2005). Oleh sebab itu, pengukuran kinerja teknologi informasi memainkan peran penting bagi peningkatan untuk kemajuan (perubahaan) ke arah yang lebih baik. Pengukuran kinerja aplikasi dilakukan terhadap fakta-fakta yang ada maka akan dihasilkan data yang berguna. Kemudian dari data tersebut dapat dilakukan analisis untuk mendapatkan informasi yang tepat mengenai keadaan kinerja teknologi informasi saat ini sehingga dapat digunakan oleh pihak manajemen perbankan dalam mengambil langkah-langkah untuk meningkatkan kinerja teknologi informasi di masa mendatang (Kumajas dan Suhardi, 2005).

Berdasarkan survei awal kepada sejumlah responden menandakan penggunaan aplikasi ini sudah bersifat menyeluruh dan memiliki integrasi untuk semua unit kerja. Kebutuhan informasi sudah sesuai dengan kebutuhan pengguna. Proses pengolahan data sudah berjalan dengan baik walaupun masih membutuhkan penambahan waktu sebelum proses penutupan transaksi setiap harinya. Modul-modul aplikasi WBS sudah dapat menangani kebutuhan pengolahan data transaksi dan kebutuhan antar bank dalam proses kliring.Kebutuhan melakukan pengukuran kinerja aplikasi WBS dimaksudkan untuk mengetahui masing-masing perspektif, yaitu kontribusi organisasi, orientasi pengguna, kesempurnaan operasional, dan orientasi masa depan dengan menggunakan metode IT Balanced Scorecard. Tujuannya adalah untuk dapat mengetahui sejauh mana kontribusi pemanfaatan aplikasi sudah dapat memberikan manfaat dan bagian-bagian proses bisnis yang masih membutuhkan perbaikan dan penyempurnaan. Mengingat aplikasi WBS memiliki peran penting meningkatkan produktivitas serta mewujudkan sasaran-sasaran kerja berupa peningkatan produktivitas kerja, ketersediaan informasi untuk pembuatan keputusan, efektivitas penggunaan dana, efisiensi proses kerja, inovatif, penyelesaian pekerjaan tepat waktu dan meningkatnya kepuasan nasabah.

Penelitian dengan metode sejenis yang pernah dilakukan sebelumnya adalah pengukuran kinerja direktorat teknologi informasi berdasarkan metode IT Balanced Scorecard di PT. Bank "x" (Persero) Tbk (Pardede \& Harsono, 2007), pengukuran tingkat dukungan teknologi informasi pada direktorat transformasi teknologi komunikasi dan informasi, direktorat jenderal pajak dengan menggunakan IT Balanced Scorecard (Hidayanto, dkk, 2010), dan evaluasi kinerja IT pada XYZ menggunakan IT Balanced Scorecard (Maula \& Ghozali, 2012). Merujuk kepada penelitian yang sudah dilakukan sebelumnya sama-sama menggunakan IT Balanced Scorecard untuk melakukan pengukuran kinerja dari penerapan teknologi informasi. Penelitian ini menitikberatkan pada sasaran-sasaran strategis perbankan dengan variabel dimensi pengukuran yang disesuaikan dengan pihak perbankan tersebut.

\section{Tinjauan Pustaka}

Pada tahun 1997, Van Grembergen dan Van Bruggen mengembangkan IT Balanced Scorecard (Information Technology Balanced Scorecard) untuk digunakan pada departemen teknologi informasi organisasi. IT Balanced Scorecard memiliki standar yang memudahkan peneliti dalam mengukur sebuah kinerja teknologi informasi (Keyes, 2005). IT Balanced Scorecard memiliki tujuan agar para pengguna dapat menyesuaikan perencanaan dan aktivitasaktivitas sistem informasi dengan tujuan dan kebutuhan organisasi, menyesuaikan usaha pengguna dengan tujuan sistem informasi, menyediakan pengukuran untuk mengevaluasi efektivitas organisasi sistem informasi, mendorong dan mempertahankan kinerja sistem informasi yang semakin meningkat, dan pencapaian hasil yang seimbang di antara kelompok stakeholder (Maula \& Ghozali, 2012). IT Balanced Scorecard adalah sebuah metodologi manajemen kinerja penerapan teknologi informasi yang dikembangkan dari metodologi balanced scorecard. IT Balanced Scorecard dapat menjabarkan dan memproyeksikan memberikan kerangka berpikir untuk menjabarkan strategi penerapan teknologi informasi perusahaan ke dalam segi operasional.

IT Balanced Scorecard terdiri dari 4 (empat) perspektif. Perspektif kontribusi organisasi adalah perspektif yang mengevaluasi kinerja IT berdasarkan pandangan dari manajemen 
eksekutif, direktur dan stakeholder. Perspektif orientasi pengguna adalah perspektif untuk mengevaluasi kinerja IT berdasarkan cara pandang pengguna yang ada. Perspektif keunggulan operasional adalah perspektif yang menilai kinerja IT berdasarkan cara pandang manajemen IT itu sendiri dan lebih jauh lagi adalah pihak yang berkaitan dengan audit dan pihak yang menetapkan aturan-aturan yang digunakan. Perspektif orientasi masa depan adalah perspektif yang menilai kinerja IT berdasarkan cara pandang dari departemen itu sendiri, yaitu pelaksanaan, para praktisi dan profesional yang ada. Perspektif ini akan menyiapkan infrastruktur organisasi yang memungkinkan tujuan-tujuan dalam tiga perspektif lainnya dapat dicapai. Kemampuan organisasi untuk dapat menghasilkan produk atau jasa di masa mendatang dengan kemampuan layanan yang memuaskan harus dipersiapkan mulai dari saat ini. Pihak manajemen harus dapat memperkirakan tren di masa mendatang dan membuat langkah-langkah persiapan dalam mengantisipasinya (Wijaya, 2007). Masing-masing perspektif ini harus diterjemahkan ke dalam metrik dan langkah-langkah yang sesuai dalam menilai situasi saat ini. Penilaian ini perlu diulang secara berkala dan selaras dengan tujuan yang ditetapkan sebelumnya (gambar 1).

\begin{tabular}{|c|c|}
\hline USER ORIENTATION & BUSINESS CONTRIBUTION \\
\hline $\begin{array}{l}\text { How do users view the IT department? } \\
\text { Mission } \\
\text { To be the preferred supplier of information systems. } \\
\text { Objectives } \\
\text {-Preferred supplier of applications } \\
\text {-Preffered supplier of operations vs proposer of best solution, } \\
\text { from whatever source } \\
\text {-Partnership withusers } \\
\text {-User satisfaction }\end{array}$ & $\begin{array}{l}\text { How does management view the IT department? } \\
\text { Mission } \\
\text { To obtain a reasonable business contribution from IT } \\
\text { investments. } \\
\text { Objectives } \\
\text { •Control of IT expenses } \\
\text { •Business value of IT projects } \\
\text {-Provision of new business capabilities }\end{array}$ \\
\hline OPERATIONAL EXCELLENCE & FUTUREORIENTATION \\
\hline $\begin{array}{l}\text { How effective and efficient are the IT processes? } \\
\text { Mission } \\
\text { To deliver effective and efficient IT applications and services. } \\
\text { Objectives } \\
\text {-Efficient and effective developments } \\
\text {-Efficient and effective operations }\end{array}$ & $\begin{array}{l}\text { How well is IT positioned to meet future needs? } \\
\text { Missions } \\
\text { To develop opportunities to answer future challenges. } \\
\text { Objectives } \\
\text { - Training and education of IT staff } \\
\text {-Expertise of IT staff } \\
\text { - Research into emerging technologies } \\
\text {-Age of application portfolio }\end{array}$ \\
\hline
\end{tabular}

Gambar 1. Perspektif Dalam IT Balanced Scorecard

Komponen IT Balanced Scorecard adalah suatu hubungan dan akibat antara tindakan yang terjadi. Hubungan ini diartikulasikan oleh dua kunci jenis tindakan: ukuran hasil dan faktor pendorong kinerja (Keyes, 2005). IT Balanced Scorecard merupakan alat yang tepat untuk mengetahui sejauh mana penerapannya sudah sesuai dengan tujuan, visi dan misi perusahaan. Untuk mencapai proses penyelarasan (penyesuaian) yang adaptif terhadap strategi bisnis dan teknologi informasi melalui IT Balanced Scorecard. IT Balanced Scorecard menyediakan pemaparan dan ulasan yang bersifat menyeluruh dan terstruktur sehingga manajer yang berkaitan dapat terus memantau perkembangan setiap aspek dari strategi penerapan teknologi informasi dengan mengacu kepada nilai dari masing-masing perspektif IT Balanced Scorecard (Gunardi, 2012).

Penyusunan perangkat evaluasi dengan metode IT Balanced Scorecard dimulai dari menganalisis tujuan bisnis perusahaan yang meliputi visi, misi, tujuan strategis, proses bisnis (Cram, 2007). Kemudian mulai menentukan ukuran dari masing-masing perspektif berdasarkan visi dan misi perusahaan, lalu langkah berikutnya yaitu menyusun pembobotan berdasarkan ukuran yang telah ditetapkan pada masing-masing parameter (Keyes, 2005) dan (Maula \& Ghozali, 2012). Keunggulan pendekatan IT Balanced Scorecard adalah mampu menghasilkan sebuah perencanaan strategi yang memiliki karakteristik komprehensif, koheren, seimbang, dan terukur (Maula \& Ghozali, 2012). Kajian dalam pengukuran kinerja melalui IT Balanced Scorecard merujuk kepada diagram hubungan sebab akibat. Melalui diagram ini dapat mengetahui hubungan sebab akibat untuk masing-masing perspektif. Perspektif yang pertama adalah perspektif keunggulan operasional, apabila keahlian dan kualitas kinerja staf 
meningkatkan akan menyebabkan peningkatan kegiatan operasional yang terkomputerisasi dan menambah dukungan pada proses bisnis, pada perspektif orientasi pengguna akan memberikan kepuasan debitur dan pengguna, dan terakhir pada perspektif kontribusi organisasi akan meningkatkan produktivitas staf dan kontribusi fungsi bisnis (gambar 2).

Diagram Sebab Akibat

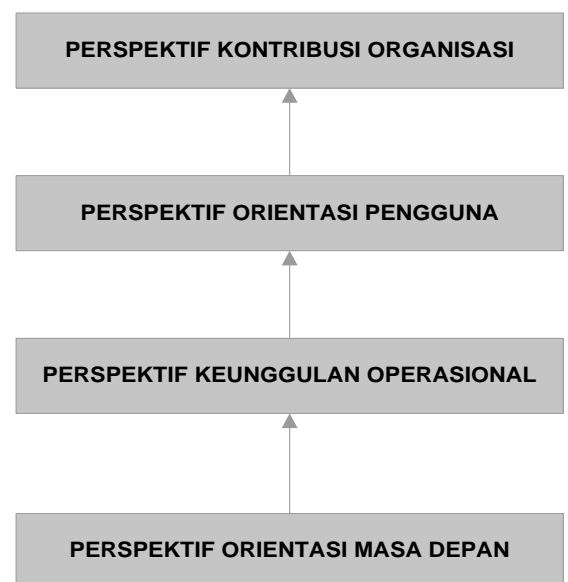

\section{Gambar Hubungan Sebab Akibat}

JIKA
Keahlian dan kualitas kinerja staf dalam
menggunakan dan memanfaatkan IT yang terus
berkembang meningkat (Perspektif orientasi masa
depan)
MAKA
Hal ini akan menghasilkan peningkatan kegiatan
operasional yang terkomputerisasi dan menambah
dukungan dalam proses bisnis
(Perspektif keunggulan operasional)
MAKA
Hal ini akan memberikan kepuasan debitur dan user
(perspektif orientasi pengguna)
MAKA
Hal ini akan meningkatkan produktifitas staf dan
kontribusi fungsi bisnis
(Perspektif kontribusi organisasi)

Gambar 2. Diagram Hubungan Sebab Akibat

\section{Metodologi Penelitian}

Penelitian ini berbentuk studi kasus dan metode penelitiannya bersifat deskriptif analitis. Teknik pengumpulan data menggunakan wawancara, observasi, dan penyebaran angket daftar pertanyaan ke sejumlah responden yang dipilih berdasarkan kemampuan dan relevan dengan pekerjaan mereka. Semua jawaban responden dapat dipertanggungjawabkan kebenarannya. Total responden berjumlah 13 orang, yang terdiri dari Asistant Manager, Accounting, Supervisor, Marketing Manager, Operasional Manager dan Executive (masingmasing 1 orang), beserta staff (5 orang), dan Customer Service (2 orang). Untuk pengukuran kinerja aplikasinya menggunakan metode IT Balanced Scorecard. Metode IT Balanced Scorecard terdiri dari perspektif kontribusi organisasi, perspektif orientasi pengguna, perspektif keunggulan operasional,dan perspektif orientasi masa depan.

Pengukuran ini diawali dengan melakukan penyelarasan (penyesuaian) visi, misi, strategi perusahaan dan divisi IT (Information Technology). Kegiatan ini untuk mengetahui tujuan sebenarnya dalam melakukan perencanaan jangka panjang terhadap semua proses bisnis. Selanjutnya mendeskripsikan isi dari strategi divisi IT dengan masing-masing perspektif IT Balanced Scorecard ke dalam diagram hubungan sebab akibat, agar memahami secara spesifik tujuan yang akan dicapai. Kemudian melakukan proses perhitungan IT Balanced Scorecard. Kemudian melanjutkan proses pengukuran kinerja aplikasi WBS tersebut. Berikutnya untuk semua nilai dari hasil pengukuran tersebut dimasukan kedalam tabel pengukuran kinerja agar dapat dijadikan rekomendasi atau masukan untuk melakukan perbaikan, mempertahankan dan meningkatkan kinerja serta investasi di waktu mendatang.

Mekanisme perhitungan untuk masing-masing perspektif diawali dengan penentuan nilai sasaran strategis untuk setiap komponen yang dinilai pada bagian ukuran strategis. Nilai sasaran strategis ini berasal dari wawancara dengan pihak manajemen (eksekutif). Untuk nilai kondisi aktual diperoleh dari perhitungan sebagai berikut: total dari perkalian antara jumlah responden yang menjawab 'ya' atau 'tidak' dengan nilai bobot. Nilai bobot 'ya' adalah 2 dan 'tidak' adalah 1. Kemudian nilai total tersebut dibagi dengan jumlah responden. Kemudian nilai total tersebut di kalikan 50\% (50\% karena skala ada 2, maka 100\%:2). Selanjutnya untuk mendapatkan nilai pencapaiannya adalah nilai hasil perkalian tersebut dibagi dengan sasaran strategis dan dijadikan dalam bentuk persentase. Untuk menghitung hasil pembobotan tujuan strategis menggunakan perumusan sbb: (1) Bobot = nilai bobot bersumber dari pihak 
manajemen perbankan, (2) Hasil Tujuan $=($ Hasil Ukuran/100) $\times$ Bobot, (3) Hasil Ukuran = Hasil rata-rata pencapaian dari pengolahan data dari masing-masing perspektif IT Balanced Scorecard, (4) Total merupakan hasil persentase dari masing-masing perspektf.

\section{Pembahasan}

Langkah awal dalam mengukur kinerja aplikasi Web Brinet System (WBS) dengan IT Balanced Scorecard pada PT. BRI Cabang Putussibau yaitu perlu melakukan konsep penyelarasan (menyesuaikan) visi, misi, strategi perusahaan dan divisi IT, untuk mengetahui tujuan sebenarnya dalam melakukan perencanaan jangka panjang terhadap semua proses bisnis. Penyelarasan antara visi perusahaan dan visi divisi IT menjadikan aplikasi WBS sebagai solusi kebutuhan perusahaan dalam memperoleh informasi. Hal ini merupakan dukungan divisi IT terhadap BRI Cabang Putussibau dengan memberikan solusi melalui peningkatan kinerja karyawan secara profesional dalam memanfaatkan IT dari penggunaan aplikasi WBS agar menjadi bank terkemuka yang meningkatkan nilai tambah secara berkelanjutan bagi masyarakat dan nasabah. Memberikan pengetahuan tentang peranan teknologi informasi dan menciptakan hubungan sosial secara langsung dengan masyarakat mengenai kebutuhan dan perkembangan teknologi informasi agar mampu meningkatkan taraf hidup masyarakat dengan cara memberikan pelatihan mengenai pemanfaatan teknologi informasi serta memberikan pelayanan yang terbaik.

Penyelarasan (penyesuaian) antara strategi perusahaan dan strategi divisi IT adalah meningkatkan sosialisasi produk melalui iklan pada website resmi diharapkan akan memberikan peningkatan posisi dan peranan perusahaan sebagai penyedia jasa manajemen untuk masyarakat, didukung produk yang lengkap dan secara konvensional, serta memberikan pelatihan kepada karyawan mengenai pentingnya teknologi informasi untuk produktifitas dan kreativitas karyawan; menggantikan operasional manual menjadi otomatisasi sehingga terwujud sustainabilitas perusahaan, dengan pertumbuhan aset dan laba serta struktur perbankan yang optimal; memberikan pelayanan prima dibidang sistem dan teknologi informasi berstandar internasional serta menjadikan sistem informasi sebagai alat strategi perusahaan dalam manajemen, perencanaan strategis, keunggulan bersaing dan pengambilan keputusan; meningkatkan otomatisasi, mengurangi kebergantungan pada aktivitas manual dengan menggunakan teknologi yang handal, serta mengikuti perkembangan teknologi informasi sehingga dapat memperbaiki infrastruktur, organisasi dan proses bisnis untuk menyediakan pelayanan yang berkualitas sesuai kebutuhan dengan cara terus berinovasi. Setelah melakukan penyelarasan visi, misi dan strategi perusahaan dengan visi, misi dan strategi divisi IT. Selanjutnya melakukan penyelarasan terhadap strategi divisi IT dengan 4 perspektif IT Balanced Scorecard. Penyelarasan ini untuk mendapatkan tujuan strategis yang sesuai untuk masing-masing strategi divisi IT (lihat tabel 1).

Tabel 1. Penyelarasan Strategi IT Dengan Perspektif IT Balanced Scorecard

\begin{tabular}{|c|c|c|}
\hline $\begin{array}{c}\text { IT Balanced } \\
\text { Scorecard }\end{array}$ & STRATEGI & $\begin{array}{c}\text { TUJUAN } \\
\text { STRATEGIS }\end{array}$ \\
\hline $\begin{array}{l}\text { Perspektif } \\
\text { Kontribusi } \\
\text { Organisasi }\end{array}$ & $\begin{array}{l}\text { a. Mengurangi aktifitas manual dan meningkatkan otomatisasi dengan } \\
\text { menggunakan teknologi baru yang sesuai kebutuhan. } \\
\text { b. Menyediakan infrastruktur yang mampu memberikan ketangkasan bisnis dan } \\
\text { efisiensi operasional. } \\
\text { c. Menanggulangi gangguan maupun resiko secara efektif dan efisien. } \\
\text { d. Meningkatkan kompetensi IT baik sumber daya maupun karyawan dan } \\
\text { infrastruktur. } \\
\text { e. Menyediakan infrastruktur dan,serta melakukan pengembangan perencanaan } \\
\text { strategis IT secara berkala. }\end{array}$ & 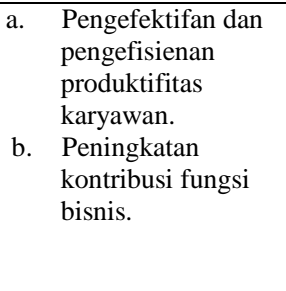 \\
\hline $\begin{array}{l}\text { Perspektif } \\
\text { Orientasi } \\
\text { Pemgguna }\end{array}$ & $\begin{array}{l}\text { a. Menanggulangi gangguan maupun maupun resiko secara efektif dan efisien. } \\
\text { b. Menyediakan infrastruktur yang mampu memberikan ketangkasan bisnis dan } \\
\text { efisiensi operasional. } \\
\text { c. Meningkatkan sumber daya baik IT maupun karyawan lainnya dan } \\
\text { infrastruktur. }\end{array}$ & $\begin{array}{ll}\text { a. } & \text { Peningkatan } \\
\text { kompetensi } \\
\text { pengguna. } \\
\text { b. Peningkatan } \\
\text { kepuasan pengguna }\end{array}$ \\
\hline $\begin{array}{l}\text { Perspektif } \\
\text { Kesempurnaan } \\
\text { Operasional }\end{array}$ & $\begin{array}{l}\text { a. Meningkatkan kompetensi IT baik sumber daya maupun infrastruktur, serta } \\
\text { melakukan pengembangan perencanaan strategis IT secara berkala. } \\
\text { b. Menyediakan infrastruktur yang potensial sehingga mampu memberikan }\end{array}$ & $\begin{array}{l}\text { a. Peningkatan } \\
\text { kegiatan } \\
\text { operasional dalam }\end{array}$ \\
\hline
\end{tabular}




\begin{tabular}{|c|c|c|c|c|}
\hline & c. & $\begin{array}{l}\text { ketangkasan bisnis dan efisiensi operasional . } \\
\text { Mengurangi aktifitas manual dan meningkatkan otomatisasi dengan } \\
\text { menggunakan teknologi baru yang sesuai kebutuhan. } \\
\text { Meminimalisir gangguan maupun resiko secara efektif dan efisien. }\end{array}$ & b. & $\begin{array}{l}\text { proses bisnis. } \\
\text { Menghasilkan } \\
\text { pengembangan } \\
\text { kualitas sistem } \\
\text { menjadi lebih baik. }\end{array}$ \\
\hline $\begin{array}{l}\text { Perspektif } \\
\text { Orientasi } \\
\text { Masa Depan }\end{array}$ & $\begin{array}{l}\text { a. } \\
\text { b. } \\
\text { c. } \\
\text { e. }\end{array}$ & $\begin{array}{l}\text { Meningkatkan sumber daya baik IT maupun karyawan lainnya dan } \\
\text { infrastruktur. } \\
\text { Meminimalisir gangguan maupun resiko secara efektif dan efisien. } \\
\text { Mengurangi aktifitas manual dan meningkatkan otomatisasi dengan } \\
\text { menggunakan teknologi baru yang sesuai kebutuhan. } \\
\text { Menyediakan infrastruktur yang potensial sehingga mampu memberikan } \\
\text { ketangkasan bisnis dan efisiensi operasional. }\end{array}$ & $\begin{array}{l}\text { a. } \\
\text { b. }\end{array}$ & $\begin{array}{l}\text { Peningkatan } \\
\text { kualitas } \\
\text { penggunaan IT } \\
\text { aplikasi WBS. } \\
\text { Peningkatan } \\
\text { pengembangan } \\
\text { sistem dengan } \\
\text { teknologi terbaru. }\end{array}$ \\
\hline
\end{tabular}

Ukuran strategis diperoleh dari penjabaran masing-masing tujuan strategis IT Balanced Scorecard sehingga menjadi beberapa ukuran. Setiap ukuran strategis harus memiliki suatu sasaran strategis, yang telah ditetapkan oleh pihak peneliti dan disetujui oleh PT. BRI Cabang Putussibau. Selanjutnya dilakukan proses pengukuran untuk menilai kinerja aplikasi Web Brinet System pada PT. BRI Cabang Putussibau. Setelah diketahui ukuran strategis dan sasaran strategis dari tiap perspektif IT Balanced Scorecard, maka perhitungan IT Balanced Scorecard dapat dilakukan. Perhitungan dilakukan dengan tujuan untuk melakukan perbandingan tiap tujuan strategis dengan kondisi yang ada pada perusahaan saat ini. Adapun gambaran umum responden dalam penelitian ini adalah karyawan PT. BRI Cabang Putussibau. Total kuesioner yang dikirim sebanyak 13 kuesioner, dan dikembalikan sebanyak 13 kuesioner, total yang dijawab sebanyak 13 kuesioner. Tabel 2 s/d tabel 5 merupakan rekapitulasi perhitungan hasil pengolahan data untuk masing-masing perspektif IT Balanced Scorecard.

Tabel 2. Hasil Pengolahan Data Perspektif Kontribusi Organisasi

\begin{tabular}{|c|c|c|c|c|}
\hline Tujuan Strategis & Ukuran Strategis & $\begin{array}{l}\text { Sasaran } \\
\text { Strategis }\end{array}$ & $\begin{array}{c}\text { Kondisi } \\
\text { Aktual }\end{array}$ & $\begin{array}{c}\text { Pencapai } \\
\text { an }\end{array}$ \\
\hline \multirow[b]{3}{*}{ Karyawan } & $\begin{array}{l}\text { A.1 Pengukuran tingkat penggunaan aplikasi WBS dapat } \\
\text { meningkatkan produktifitas kerja bagi karyawan }\end{array}$ & $90 \%$ & $88 \%$ & $97,77 \%$ \\
\hline & $\begin{array}{l}\text { A.2 Output/hasil dapat membantu manajer dalam mengambil } \\
\text { keputusan. }\end{array}$ & $95 \%$ & $80,5 \%$ & $84,73 \%$ \\
\hline & A.3 Pengefektifan penggunaan dana pengembangan aplikasi WBS & $100 \%$ & $76,5 \%$ & $80,52 \%$ \\
\hline TOTAL & $263,02 \%$ & & & \\
\hline RATA-RATA & $87,67 \%$ & & & \\
\hline \multirow{5}{*}{$\begin{array}{c}\text { B.Peningkatan } \\
\text { kontribusi } \\
\text { berorientas } \\
\text { i fungsi } \\
\text { bisnis }\end{array}$} & B.1 Realisasi biaya lebih kecil daripada anggarannya operasional & $95 \%$ & $76,5 \%$ & $80,52 \%$ \\
\hline & $\begin{array}{l}\text { B.2 Penggunaan dana pengembangan alpikasi WBS di PT. BRI } \\
\text { Cabang Putussibau sudah efektif }\end{array}$ & $90 \%$ & $88 \%$ & $97,77 \%$ \\
\hline & B.3 Aplikasi WBS menjadi kekuatan dalam mengelola data & $90 \%$ & $84,5 \%$ & $93,88 \%$ \\
\hline & TOTAL & & & $272,17 \%$ \\
\hline & RATA-RATA & & & $90,72 \%$ \\
\hline
\end{tabular}

Tabel 3. Hasil Pengolahan Data Perspektif Orientasi Pengguna

\begin{tabular}{|c|c|c|c|c|}
\hline Tujuan Strategis & Ukuran Strategis & $\begin{array}{l}\text { Sasaran } \\
\text { Strategis }\end{array}$ & $\begin{array}{c}\text { Kondisi } \\
\text { Aktual }\end{array}$ & $\begin{array}{l}\text { Pencapai } \\
\text { an }\end{array}$ \\
\hline \multirow{3}{*}{$\begin{array}{l}\text { A. Peningkatan } \\
\text { Kepuasan } \\
\text { Nasabah }\end{array}$} & A.1 Nasabah merasa puas dengan pelayanan jasa PT. BRI Cabang & & & \\
\hline & Putussibau & $95 \%$ & $92 \%$ & $96,84 \%$ \\
\hline & $\begin{array}{l}\text { A.2 Nasabah merasa puas jasa yang ditawarkan jasa PT. BRI Cabang } \\
\text { Putussibau lebih baik daripada jasa yang ditawarkan oleh bank lain }\end{array}$ & $95 \%$ & $92 \%$ & $96,84 \%$ \\
\hline TOTAL & $193,68 \%$ & & & \\
\hline RATA-RATA & $96,84 \%$ & & & \\
\hline \multirow[t]{5}{*}{$\begin{array}{l}\text { B. Peningkatan } \\
\text { kompetensi } \\
\text { pengguna }\end{array}$} & $\begin{array}{l}\text { B.1 Setelah menggunakan aplikasi WBS karyawan selalu pulang } \\
\text { tepat waktu realisasi biaya lebih kecil daripada anggarannya } \\
\text { operasional }\end{array}$ & $90 \%$ & $80,5 \%$ & $89,44 \%$ \\
\hline & $\begin{array}{l}\text { B.2 Dengan menggunakan aplikasi WBS karyawan menjadi lebih } \\
\text { kreatif dan mampu berfikir sistematis }\end{array}$ & $85 \%$ & $84,5 \%$ & $93,88 \%$ \\
\hline & $\begin{array}{l}\text { B.3 Dengan menggunakan aplikasi WBS karyawan selalu } \\
\text { menyelesaikan kerjaan sesuai dengan rencana yang disusun }\end{array}$ & $90 \%$ & $88 \%$ & $97,77 \%$ \\
\hline & TOTAL & & & $281,09 \%$ \\
\hline & RATA-RATA & & & $93,69 \%$ \\
\hline
\end{tabular}


Tabel 4. Hasil Pengolahan Data Perspektif Kesempurnaan Operasional

\begin{tabular}{|c|c|c|c|c|}
\hline Tujuan Strategis & Ukuran Strategis & $\begin{array}{l}\text { Sasaran } \\
\text { Strategis }\end{array}$ & $\begin{array}{c}\text { Kondisi } \\
\text { Aktual }\end{array}$ & $\begin{array}{l}\text { Pencapai } \\
\text { an }\end{array}$ \\
\hline \multirow{3}{*}{$\begin{array}{l}\text { A. Peningkatan } \\
\text { kegiatan } \\
\text { operasional yang } \\
\text { terkomputerisasi }\end{array}$} & $\begin{array}{l}\text { A.1 PT. Bank Rakyat Indonesia Cabang Putussibau } \\
\text { menggunakan sistem terkomputerisasi vang memadai }\end{array}$ & $90 \%$ & $88 \%$ & $97.77 \%$ \\
\hline & $\begin{array}{l}\text { A.2 Dengan menggunakan aplikasi WBS pelaksanaan } \\
\text { pelayanan jasa dan proses pengolahan data selalu tepat waktu }\end{array}$ & $90 \%$ & $80,5 \%$ & $89,44 \%$ \\
\hline & A.3 Aplikasi mudah ditangani apabila terjadi masalah & $90 \%$ & $88 \%$ & $97,77 \%$ \\
\hline TOTAL & $284,98 \%$ & & & \\
\hline RATA-RATA & $94,99 \%$ & & & \\
\hline \multirow{3}{*}{$\begin{array}{l}\text { B.Pengembangan } \\
\text { kualitas sistem } \\
\text { menjadi lebih } \\
\text { baik }\end{array}$} & $\begin{array}{l}\text { B.1 Setelah menggunakan aplikasi WBS karyawan selalu } \\
\text { pulang tepat waktu realisasi biaya lebih kecil daripada } \\
\text { anggarannya operasional }\end{array}$ & $95 \%$ & $92 \%$ & $96,84 \%$ \\
\hline & $\begin{array}{l}\text { B.2 Dengan menggunakan aplikasi WBS karyawan menjadi } \\
\text { lebih kreatif dan mampu berfikir sistematis }\end{array}$ & $90 \%$ & $88 \%$ & $97,77 \%$ \\
\hline & TOTAL & & & $\frac{194,61 \%}{0730 \%}$ \\
\hline
\end{tabular}

Tabel 5. Hasil Pengolahan Data Perspektif Orientasi Masa Depan

\begin{tabular}{|c|c|c|c|c|}
\hline Tujuan Strategis & Ukuran Strategis & $\begin{array}{c}\text { Sasaran } \\
\text { Strategis }\end{array}$ & $\begin{array}{c}\text { Kondisi } \\
\text { Aktual } \\
\end{array}$ & $\begin{array}{l}\text { Pencapai } \\
\text { an }\end{array}$ \\
\hline \multirow{2}{*}{$\begin{array}{l}\text { A. Peningkatan kualitas } \\
\text { penggunaan IT } \\
\text { WBS } \\
\end{array}$} & A.1 Keahlian karyawan meningkat & $90 \%$ & $88 \%$ & $97,77 \%$ \\
\hline & $\begin{array}{l}\text { A.2 Berkurangnya kesalahan dan informasi yang diperoleh } \\
\text { cepat dan tepat }\end{array}$ & $95 \%$ & $92 \%$ & $96,84 \%$ \\
\hline TOTAL & $194,61 \%$ & & & \\
\hline RATA-RATA & \multicolumn{4}{|c|}{$97,30 \%$} \\
\hline \multirow{4}{*}{$\begin{array}{l}\text { B. Peningkatan sistem } \\
\text { dengan } \\
\text { pemanfaatan } \\
\text { teknologi baru } \\
\end{array}$} & B.1 Terus mengikuti perkembangan IT dimasa mendatang & $95 \%$ & $92 \%$ & $96,84 \%$ \\
\hline & B.2 Peningkatan kinerja dengan pemanfaatan teknologi baru & $90 \%$ & $88 \%$ & $97,77 \%$ \\
\hline & TOTAL & & & $194,61 \%$ \\
\hline & RATA-RATA & & & $97,30 \%$ \\
\hline
\end{tabular}

Selanjutnya dilakukan pembobotan tujuan strategis pada setiap perspektif IT Balanced Scorecard. Bobot tersebut ditetapkan berdasarkan hasil pengamatan selama penelitian di PT. BRI Cabang Putussibau yang kemudian disetujui oleh pihak manajemen. Bobot ditentukan untuk mencari hasil tujuan dari setiap hasil ukuran. Bobot tersebut diperoleh berdasarkan kesepakatan dan persetujuan pihak PT. Bank Rakyat Indonesia Cabang Putussibau (tabel 6). Selanjutnya akan dicari hasil tingkat pemenuhan target pada masing-masing perspektif IT Balanced Scorecard (tabel 7) dan hasil pengukuran kinerja aplikasi WBS sampai kepada total nilai IT Balanced Scorecard (tabel 8).

Tabel 6. Hasil Pembobotan Tujuan Strategis

\begin{tabular}{|c|c|c|c|c|}
\hline Perspektif & Tujuan strategis & Bobot & $\begin{array}{c}\text { Hasil } \\
\text { Ukuran }\end{array}$ & $\begin{array}{c}\text { Hasil } \\
\text { Tujuan } \\
\end{array}$ \\
\hline \multirow[t]{3}{*}{ Kontribusi Organisasi } & Pengefektifan dan pengefisienan produktifitas karyawan & $45 \%$ & $87.67 \%$ & $39.45 \%$ \\
\hline & Peningkatan kontribusi berorientasi fungsi bisnis & $55 \%$ & $90.72 \%$ & $49.89 \%$ \\
\hline & TOTAL & & & $89.34 \%$ \\
\hline \multirow[t]{3}{*}{ Orientasi Pengguna } & Peningkatan Kepuasan Nasabah & $50 \%$ & $96.84 \%$ & $48.42 \%$ \\
\hline & Peningkatan kompetensi pengguna & $50 \%$ & $93.69 \%$ & $46.84 \%$ \\
\hline & TOTAL & & & $95.26 \%$ \\
\hline \multirow[t]{3}{*}{ Kesempurnaan Operasional } & Peningkatan kegiatan operasional yang terkomputerisasi & $40 \%$ & $94.99 \%$ & $37.99 \%$ \\
\hline & Peningkatan kegiatan operasional dalam proses bisnis & $60 \%$ & $97.30 \%$ & $58.38 \%$ \\
\hline & TOTAL & & & $96.37 \%$ \\
\hline \multirow[t]{3}{*}{ Orientasi Masa Depan } & Peningkatan kualitas penggunaan IT WBS & $60 \%$ & $97.30 \%$ & $58.38 \%$ \\
\hline & Peningkatan sistem dengan pemanfaatan teknologi baru & $40 \%$ & $97.30 \%$ & $38.92 \%$ \\
\hline & TOTAL & & & $97.30 \%$ \\
\hline
\end{tabular}

Tabel 7. Hasil Pengukuran

\begin{tabular}{cc}
\hline Perpektif & Hasil Pengukuran \\
\hline Kontribusi Organisasi & $22.33 \%$ \\
\hline Orientasi Pengguna & $23.81 \%$ \\
\hline Keunggulan Operasional & $24.09 \%$ \\
\hline Orientasi Masa Depan & $24.32 \%$ \\
\hline TOTAL & $\mathbf{9 4 . 5 5 \%}$
\end{tabular}


Tabel 8. Hasil Pengukuran Kinerja Aplikasi WBS

\begin{tabular}{|c|c|c|c|c|c|c|c|}
\hline Tujuan Strategis & Ukuran strategi & $\begin{array}{l}\text { Sasa- } \\
\text { ran } \\
(\%)\end{array}$ & $\begin{array}{l}\text { Aktual } \\
(\%)\end{array}$ & $\begin{array}{l}\text { Penca- } \\
\text { paian } \\
(\%)\end{array}$ & $\begin{array}{c}\text { Bobot } \\
\text { tujuan } \\
(\%)\end{array}$ & $\begin{array}{c}\text { Hasil } \\
\text { tujuan } \\
(\%)\end{array}$ & $\begin{array}{l}\text { Hasil } \\
\text { perspek- } \\
\text { tif }(\%)\end{array}$ \\
\hline \multicolumn{8}{|c|}{ Perspektif Kontribusi Organisasi $(25 \%)=22,33 \%$} \\
\hline \multirow{3}{*}{$\begin{array}{l}\text { Pengefektifan dan } \\
\text { pengefisienan } \\
\text { produktifitas } \\
\text { karyawan }\end{array}$} & $\begin{array}{l}\text { \%penggunaan aplikasi WBS dapat } \\
\text { meningkatkan produktifitas kerja bagi } \\
\text { karyawan }\end{array}$ & 90 & 88 & 97,77 & \multirow{3}{*}{45} & \multirow{3}{*}{39,45} & \multirow{7}{*}{89,34} \\
\hline & $\begin{array}{l}\text { \%Output/hasil dapat membantu manajer } \\
\text { dalam mengambil keputusan }\end{array}$ & 95 & 80,5 & 84,73 & & & \\
\hline & $\begin{array}{l}\text { \%Pengefektifan penggunaan dana } \\
\text { pengembangan aplikasi WBS }\end{array}$ & 100 & 76,5 & 80,52 & & & \\
\hline \multirow{4}{*}{$\begin{array}{l}\text { Peningkatan } \\
\text { kontribusi } \\
\text { berorientasi fungsi } \\
\text { bisnis }\end{array}$} & $\begin{array}{l}\text { \%Realisasi biaya lebih kecil daripada } \\
\text { anggarannya operasional }\end{array}$ & 95 & 76,5 & 80,52 & \multirow{4}{*}{55} & & \\
\hline & \%Penggunaan dana pengembangan alpikasi & 90 & 88 & 97,77 & & & \\
\hline & $\begin{array}{l}\text { WBS di PT. Bank Rakyat Indonesia sudah } \\
\text { efektif }\end{array}$ & & & & & 49,89 & \\
\hline & $\begin{array}{l}\text { \%Aplikasi WBS menjadi kekuatan dalam } \\
\text { mengelola data }\end{array}$ & 90 & 84,5 & 93,88 & & & \\
\hline \multicolumn{8}{|c|}{ Perpektif Orientasi Pengguna $(25 \%)=23,81 \%$} \\
\hline \multirow[t]{2}{*}{$\begin{array}{l}\text { Peningkatan } \\
\text { Kepuasan } \\
\text { Nasabah }\end{array}$} & $\begin{array}{l}\text { \% Nasabah merasa puas dengan pelayanan } \\
\text { jasa PT. Bank Rakyat Indonesia Cabang } \\
\text { Putussibau }\end{array}$ & 95 & 92 & 96,84 & \multirow[b]{2}{*}{50} & \multirow[b]{2}{*}{48,42} & \multirow{5}{*}{95,26} \\
\hline & $\begin{array}{l}\text { \% Nasabah merasa puas jasa yang } \\
\text { ditawarkan jasa PT. Bank Rakyat Indonesia } \\
\text { Cabang Putussibau lebih baik daripada jasa } \\
\text { yang ditawarkan oleh bank lain }\end{array}$ & 95 & 92 & 96,84 & & & \\
\hline \multirow{3}{*}{$\begin{array}{l}\text { Peningkatan } \\
\text { kompetensi } \\
\text { pengguna }\end{array}$} & $\begin{array}{l}\text { \%Setelah menggunakan aplikasi WBS } \\
\text { karyawan selalu pulang tepat waktu }\end{array}$ & 90 & 80,5 & 89,44 & \multirow{3}{*}{50} & \multirow{3}{*}{46,84} & \\
\hline & $\begin{array}{l}\text { \%Dengan menggunakan aplikasi WBS } \\
\text { karyawan menjadi lebih kreatif dan mampu } \\
\text { berfikir sistematis }\end{array}$ & 85 & 84,5 & 93,88 & & & \\
\hline & $\begin{array}{l}\text { \%Dengan menggunakan aplikasi WBS } \\
\text { karyawan selalu menyelesaikan kerjaan } \\
\text { sesuai dengan rencana yang disusun }\end{array}$ & 90 & 88 & 97,77 & & & \\
\hline \multicolumn{8}{|c|}{ Perpektif Penyempurnaan Operasional $(25 \%)=24,09 \%$} \\
\hline \multirow{3}{*}{$\begin{array}{l}\text { Peningkatan } \\
\text { kegiatan } \\
\text { operasional yang } \\
\text { terkomputerisasi }\end{array}$} & $\begin{array}{l}\text { \%PT. Bank Rakyat Indonesia Cabang } \\
\text { Putussibau menggunakan sistem } \\
\text { terkomputerisasi yang memadai }\end{array}$ & 90 & 88 & 97,77 & \multirow{3}{*}{40} & \multirow{3}{*}{37,99} & \multirow{5}{*}{96,37} \\
\hline & $\begin{array}{l}\text { \%Dengan menggunakan aplikasi WBS } \\
\text { pelaksanaan pelayanan jasa dan proses } \\
\text { pengolahan data selalu tepat waktu }\end{array}$ & 90 & 80,5 & 89,44 & & & \\
\hline & $\begin{array}{l}\% \text { Aplikasi mudah ditangani apabila terjadi } \\
\text { masalah }\end{array}$ & 90 & 88 & 97,77 & & & \\
\hline \multirow{2}{*}{$\begin{array}{l}\text { Peningkatan } \\
\text { kegiatan } \\
\text { operasional dalam } \\
\text { proses bisnis }\end{array}$} & $\begin{array}{l}\text { \%Aplikasi WBS berperan penting dalam } \\
\text { proses bisnis }\end{array}$ & 95 & 92 & 96,84 & \multirow[b]{2}{*}{60} & \multirow[b]{2}{*}{58,38} & \\
\hline & $\begin{array}{l}\text { \%PT. Bank Rakyat Indonesia Cabang } \\
\text { Putussibau tanggap terhadap keinginan dan } \\
\text { kebutuhan nasabah }\end{array}$ & 90 & 88 & 97,77 & & & \\
\hline \multicolumn{8}{|c|}{ Perspektif Orientasi Masa Depan $(25 \%)=24,32 \%$} \\
\hline \multirow{2}{*}{$\begin{array}{l}\text { Peningkatan } \\
\text { kualitas } \\
\text { pengguna-an IT } \\
\text { WBS }\end{array}$} & \%Keahlian karyawan meningkat & 90 & 88 & 97,77 & \multirow[b]{2}{*}{60} & \multirow[b]{2}{*}{58,38} & \\
\hline & $\begin{array}{l}\text { \% Berkurangnya kesalahan dan informasi } \\
\text { yang diperoleh cepat dan tepat }\end{array}$ & 95 & 92 & 96,84 & & & 97,30 \\
\hline \multirow{3}{*}{$\begin{array}{l}\text { Peningkatan } \\
\text { sistem dengan } \\
\text { pemanfaatan } \\
\text { teknologi baru }\end{array}$} & $\begin{array}{l}\text { \% Terus mengikuti perkembangan IT dimasa } \\
\text { mendatang }\end{array}$ & 95 & 92 & 97,77 & \multirow[t]{2}{*}{40} & \multirow[t]{2}{*}{38,92} & \\
\hline & $\begin{array}{l}\text { \%Peningkatan kinerja dengan pemanfaatan } \\
\text { teknologi baru }\end{array}$ & 90 & 88 & 96,84 & & & \\
\hline & \multicolumn{7}{|c|}{ Nilai IT Balanced Scorecard $=94,55 \%$} \\
\hline
\end{tabular}

Setelah dilakukan pengukuran kinerja melalui keempat perpektif yang ada pada IT Balanced Scorecard, maka dapat dilakukan evaluasi hasil pengukuran terhadap hasil rata-rata pencapaian yang diperoleh dari masing-masing perpektif. Perspektif Kontribusi Organisasi memiliki nilai $89,34 \%$ menunjukan bahwa pencapaian pada perspektif kontribusi organisasi perusahaan sudah sangat baik, yaitu pada level very good. Ini dapat terjadi karena pengefektifan dan pengefisienan produktivitas karyawan, serta sesuai rencana. Selain itu, juga peningkatan kontribusi berorientasi fungsi bisnis dalam menunjang kebutuhan pengembangan sistem pada 
PT. BRI Cabang Putussibau.Perspektif Orientasi Pengguna memiliki nilai 95,26\% menunjukan bahwa pencapaian pada perspektif kontribusi organisasi sudah sangat baik, yaitu pada level very good. Ini dapat terjadi karena tingkat kepuasan pengguna terhadap sistem cukup tinggi, frekuensi pelatihan pengguna yang terbilang rutin, serta seringnya keterlibatan pengguna dalam pengembangan sistem, sehingga peningkatan kompetensi pengguna khususnya dibidang teknologi informasi akan mengurangi kesalahan serta PT. BRI Cabang Putussibau mampu bersaing secara kompetitif. Perpektif Penyempurnaan Operasional berada pada level very good dengan hasil 96,37\%. Hal ini dapat terjadi karena peningkatan dukungan dan pemeliharaan terhadap peningkatan kegiatan operasional yang terkomputerisasi serta peningkatan kegiatan operasional dalam proses bisnis yang baik sehingga hasil pengembangan menjadi lebih baik dan berkualitas, dengan demikian keunggulan yang diberikan teknologi informasi akan semakin terlihat dengan hasil pengukuran kinerja aplikasi WBS pada PT. BRI Cabang Putussibau yang berada pada level very good. Selanjutnya Perspektif Orientasi Masa Depan memiliki hasil $97,30 \%$, terlihat bahwa pencapaian perspektif orientasi masa depan juga berada pada level very good. Hal ini dapat terjadi karena peningkatan kualitas teknologi informasi, yang didukung dengan karyawan yang berkualitas serta memiliki cukup banyak pengalaman dibidangnya. Selain itu, PT. BRI Cabang Putussibau sering melakukan pelatihan untuk menambah keahlian karyawan teknologi informasi. Seringnya perusahaan melakukan pengembangan sistem juga turut mendukung pencapaian yang baik pada perspektif ini dengan terus mengikuti perkembangan teknologi informasi dimasa mendatang.

Penggunaan aplikasi WBS mampu memberikan kontribusi terhadap organisasi, mendukung orientasi pengguna, mendukung kegiatan operasional, dan mampu menjadi keunggulan bersaing dimasa depan. Hal ini dapat dinilai dari perolehan pengukuran dari masing-masing perspektif yaitu kontribusi organisasi sebesar $89,34 \%$ dengan hasil pengukuran masing-masing perspektif sebesar $22,33 \%$, orientasi pengguna sebesar $95,26 \%$ dengan hasil pengukuran dari masing-masing perspektif sebesar 23,81\%, keunggulan operasional sebesar $96,37 \%$ dengan hasil pengukuran dari masing-masing perspektif sebesar $24,09 \%$, dan orientasi masa depan sebesar $97,30 \%$ dengan hasil pengukuran dari masing-masing perspektif sebesar 24,32\%. Hasil akhir dalam pengukuran kinerja aplikasi WBS dengan IT Balanced Scorecard memperlihatkan pencapaian nilai IT Balanced Scorecard PT. BRI Cabang Putussibau sebesar $94,55 \%$ dan nilai ini telah berada pada level A atau very good.

\section{Kesimpulan}

Target hasil pengukuran dari masing-masing perspektif sebesar $25 \%$ yang diperoleh dari 100\%:4 perspektif. Perspektif tertinggi adalah orientasi masa depan yaitu sebesar 24,32\%, kedua adalah keunggulan operasional yaitu sebesar $24,09 \%$, ketiga adalah orientasi pengguna sebesar 23,81\%, dan terendah adalah kontribusi organisasi sebesar 22,33\%. Dari ketiga perspektif yang tidak mencapai target pengukuran diakibatkan karena kinerja aplikasi belum maksimal dalam mendukung kinerja karyawannya, serta produktivitas karyawannya belum efektif dan efisien. Perspektif kontribusi organisasi memperoleh hasil pengukuran terendah karena belum efektifnya penggunaan dana pengembangan aplikasi WBS serta realisasi biaya lebih kecil dari pada anggaran operasionalnya.Namun penerapan aplikasi WBS saja tidak cukup untuk memenuhi kebutuhan di masa yang akan datang, perlu didukung dengan sumber daya manusia yang kompeten sehingga mampu melakukan perencanaan dengan baik dalam menghadapi perubahan yang terjadi secara terus menerus.

\section{Referensi}

Cram, Alec. 2007. The IT Balanced Scorecard Revisited. Information Systems Control Journal, Vol 5, 2007, ISACA.

Gunardi, Dedi Sulistyo S., Taryana Suryana. 2012. Usulan Peta Strategi Teknologi Informasi Menggunakan Pendekatan Analisis Critical Success Factor (CSF) dan IT Balanced Scorecard (Studi Kasus Pada PT. Sola Gratia Bandung). Jurnal Majalah Ilmiah Unikom, Vol 10 No. 1 Pebruari 2012, Universitas Komputer Indonesia Bandung. 
Hidayanto, A Nizar., Ahmadin, Yudhiansyah., dan Jiwanggi, Meganingrum Arista. 2010. Pengukuran Tingkat Dukungan Teknologi Informasi pada Direktorat Transformasi Teknologi Komunikasi dan Informasi Direktorat Jenderal Pajak dengan Menggunakan IT Balanced Scorecard. Journal of Information Systems, Vol 6 Issues 2, October 2010, Fakultas Ilmu Komputer, Universitas Indonesia.

Keyes, Jessica. 2005. Implementing The IT Balanced Scorecard: Aligning IT With Corporate Strategy. Auerbach Publications, Taylor \& Francis Group.

Kumajas, Sondy dan Suhardi. 2005. Bahasan Utama Dalam Kinerja Teknologi Informasi Menggunakan IT-BSC. Prosiding Konferensi Nasional Teknologi Informasi dan Komunikasi Indonesia, ITB, 3-4 Mei, Hal 372-376.

Maula, Khikmatul \& Ghozali, Khakim. 2012. Evaluasi Kinerja IT pada PT. XYZ Menggunakan IT Balanced Scorecard. Jurnal Teknik Pomits, Vol 1 No. 1, ITS.

Pardede \& Harsono. 2007. Pengukuran Kinerja Direktorat Teknologi Informasi Berdasarkan Metode IT Balanced Scorecard di PT. Bank "x" (persero) Tbk. Jurnal Ilmiah Ilmu Komputer, Vol.5 No.1, Hal 21-28.

Wijaya, Rahmadi. 2007. Analisis Model IT Menggunakan Balanced Scorecard untuk Pengembangan Sistem Teknologi Informasi. Jurnal Sistem Informasi, ISSN: 19071221, Vol 2 No. 1 Maret 2007, Universitas Kristen Maranatha Bandung. 